\title{
COMPARATIVE STUDY BETWEEN THE PAPILLARY MUSGLES OF THE RIGHT VENTRICLE AND THE LEFT VENTRICLE PAPILLARY MUSGLES
}

\section{Tobă Marius', Iliescu Dan Marcel1, Bordei Petru1, Popescu-Ghiriloaie Gristina1, Gheorghițescu [Jancă] Ruxandra'}

${ }^{1}$ Faculty of Medicine, University "Ovidius" of Constanta

Ruxandra Gheorghitescu

Faculty of Medicine, Univeristy ,, Ovidius” of Constanta, Universitatii Alee No. 1, Campus B, Constanta, Romania email: Rux.gheorghitescu@gmail.com phone: +40722592424

\begin{abstract}
We used formalinized heart dissection obtained from forensic laboratory in Constanta, analyzing the papillary muscles and their tendon chordae. We studied at the papillary muscles the number of forms that could be in single or multiple muscular bodies, encountering more than five body muscles in a papillary muscle group. We measured using caliper graduated in millimeters, the height of each papillary muscle body (from the base to its upper end) and its thickness at the base and at its upper extremity. Chordae tendon we examined in terms of their origin and number at the level of each papillary muscle, the dimensions (length and thickness), orientation and how they end at the atrioventricular valves. We noted the presence of "false"chordae tendineae, which were disposed between the papillary muscle and the ventricular wall. The results were compared with data in the literature that I had the opportunity to consult
\end{abstract}

Keywords: papillary muscles, ventricle, comparison, tendon chordae

\section{Introduction}

This study is useful for anatomists, cardiologists and cardiac surgeons. The normal functioning of the mitral valve depends on the anatomical and mechanical integrity of the papillary muscles. Modern cardiac surgery requires a clearer understanding of the anatomy of the papillary muscles, the tendon cordae and the mitral valve, the variants that they can present, which are of considerable importance because of their role in the surgical treatment of mitral valve prolapse and replacement of the mitral valve (1).

The shape of the papillary muscles affects the blood flow, the chances of obstruction of the left ventricle are higher in fan-shaped papillary hypertrophy (aspect that we have not found) and the papillary muscles with a large apex. The papillary muscle, which facilitates cardiovascular physiology with minimal obstruction to blood flow, is conical, inserted on the ventricular wall, closer to the ventricle tip, leaving the center of the cavity (2) free. (3), who studied the variations mitral valve's papillary muscles variations in 100 cases, states that the mitral apparatus, including papillary muscles, is just as unique to each individual as their own fingerprints. 


\section{Material and method}

We used formalinized heart dissection obtained from forensic laboratory in Constanta, analyzing the papillary muscles and their tendon chordae.

\section{PERSONAL RESULTS AND DISCUSSION}

We compared the morphological characteristics of the left and right papillary muscles, in the number and shape of their height and their thickness, at the base and their upper extremity.

\section{Comparison between the papillary muscles right and left}

The right anterior papillary muscles were most frequent with $41.95 \%$ than the left, and if left papillary muscles were more frequent double the $33.81 \%$ than the righteous. Triple and quadruple papillary muscles I found more frequently in the left anterior papilary, where the triple was $2.33 \%$ and $2.35 \%$ for those with quadruple. Quintuple papillary muscles I never found in the anterior left papillary. The conical shape of the anterior left papillary muscle was more common with $4.83 \%$ than in the anterior right ones and $4.96 \%$ for cylindrical papillary muscles. For irregular fusiform forms, I found that left papillary muscles were less frequent than the anterior straight with $1.40 \%$ for irregular papillary and $0.58 \%$ for fusiform papillaries. Left anterior papillary muscles showed fewer forms than righteones, when encountering their arched forms, a truncated cone, the "Y" back in ,V" back. As ,the torch" I have not found until just prior to the papillary muscles.

Double papillary muscles, shaped like the letter „H” I found it in one case on both sides, as in "N" have found only in the left anterior papillary muscles, and the shape of the letter "N" returned I found in one case in the right anterior papillary muscles (muscles just $0.74 \%$ of double) and 5 cases from the left $(7.58 \%$ of the left double muscles). Right anterior papillary muscles were double the same form in $19.05 \%$ of cases where the same form as in anterior left in $25.39 \%$ of cases, so a difference of $6.34 \%$ for the left papillary.
Thebase of the right anterior papillary muscle was unique in $53.33 \%$ of cases, those being left with less disposable $18.78 \%$ of cases. For bases with more roots, the left papillary muscles showed higher percentages than straight papillaries, with $28.71 \%$ in cases with two roots, with $1.32 \%$ in cases with three roots and $2.34 \%$ in 4 cases roots.

At its height the papillary muscles, right and left, I found that if papillary unique height was higher by an average of $3 \mathrm{~mm}$ in favor of the left, where the papillary muscles heights were similar, and if papillary muscle triple, the difference between dimensions, minimum and maximum was $2.5 \mathrm{~mm}$ for the left. After (4) papillary muscle length decreases with increasing their assertion that I could not confirm it, finding multiple papillary muscles that had height greater than that of unique papillary muscle. The thickness of the base on anterior papillary muscles was higher for single left papillary muscles on average 4 $\mathrm{mm}, 2.4 \mathrm{~mm}$ at the double to triple papillary muscles finding it higher in papillary muscles just average 2.3. The thickness of the papillary muscles at end of the top in the ventricles, in the previous case of single papillary muscle was greater for the posterior papillary muscles up to 6 $\mathrm{mm}$, and in the case of double papillary muscle, the posterior had greater height by up to $1.2 \mathrm{~mm}$. In cases of triple papillary muscles, the lower was the posterior muscle up to $2.8 \mathrm{~mm}$.

\section{Comparison between the left and right posterior papillary muscles}

Posterior papillary muscles were more frequent unique with $29.41 \%$ than the left, and in left papillary muscles were the most frequent double by $17.43 \%$ than the righteones. Triple papillary muscles I have found more frequently in left posterior papillaries with $2.65 \%$ and in the case of quadruple, were more frequent with $13.64 \%$ then the left ones. Subsequent to the papillary muscles just have not found the papillary muscles with five bodies.

The conical shape of the papillary muscles of the right hind was more frequent with $15.24 \%$ more than the left posterior papillary muscle, cylindrical reduced in left posterior papillaries with $11.18 \%$ than the righteones. If irregular shapes and curved I found that left papillary muscles were more frequent than the anterior 
straight with $1.07 \%$ for irregular papillary and $0.99 \%$ for papillary arcuated. Left posterior papillary muscles showed a total of 2 cases in the form of „N" returned, the left showing 5 cases of this form. The rightones showed 2 cases of posterior papillary muscle in shape of'Y" back, left papillaries not showing this form, but had 2 cases of papillary of the shape of „N" letter. As ,the torch” I found at both papillary muscles righteous, and the shape of the letter „H” I found at the posterior papillary muscles.

Double posterior papillary muscles had just the same form in $36.84 \%$ of cases, and in left papillaries $i$ found this shape omly in $40.0 \%$ of cases, so more frequently with $3.16 \%$. The base of the anterior papillary muscles was unique in $34.55 \%$ of the cases of the, and for left ones most common being in $19.37 \%$ of the cases. For bases with multiple roots, showed in the left papillary muscles showed lower percentages than right ones with $35,90 \%$ in cases with two roots, with $17.95 \%$ in cases with three roots, and never found with four roots in the left papillaries.

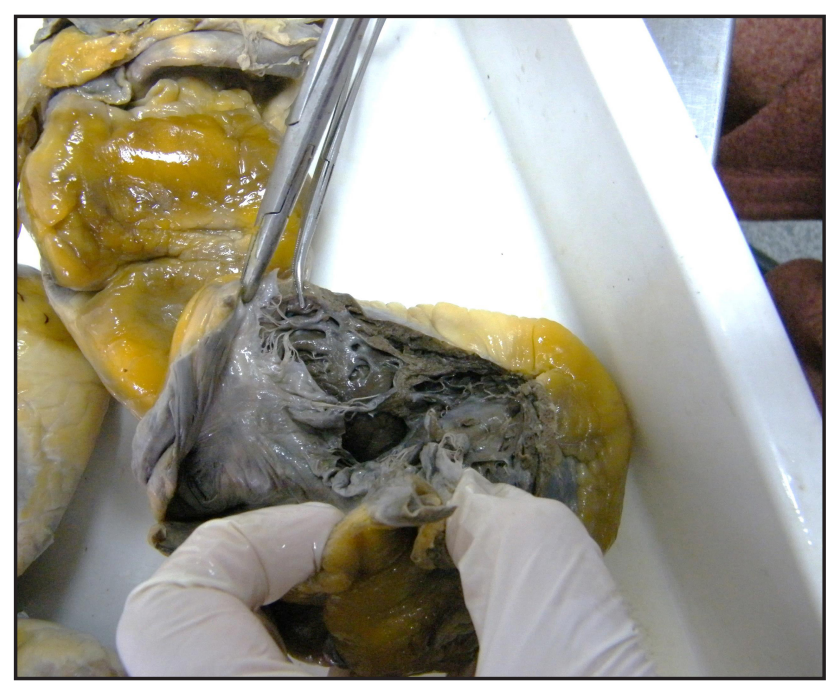

Figure 1. Double right anterior papillary muscle on the side of valve chordae to emerge from its peak, showing a lateral parietal stringing above its base. Medial papillary has in the tip, two cones that fall muscle valve chordae.

One valve chordae beam before it falls off, above his means and from the anterolateral.

At its height the right and left posterior papillary muscle, we found that if unique papillary height was higher by an average of $2.5 \mathrm{~mm}$ then the left, if left papillary papillary muscles double heights were higher by up to 5 $\mathrm{mm}$ and in the case of papillary muscles triple difference between minimum and maximum size was $1.5 \mathrm{~mm}$ in favor of the left. Posterior papillary muscle thickness at the base of the two ventricles, it was higher for single and double left papillary muscles. on average by $2.7 \mathrm{~mm}$ to the papillary muscles finding a triple higher straight papillary muscles, with an average of 2.5. The thickness of the upper end of the posterior papillary muscle of the two ventricles, in the case of single papillary muscle was greater for the posterior papillary muscles up to $4.5 \mathrm{~mm}$, and in the case of double papillary muscle, the posterior had greater height up to $4.2 \mathrm{~mm}$. For the trple posterior papillary muscle the height was higher by up to $2.7 \mathrm{~mm}$.

The tendon chordae

In the right ventricle I will refer in particular to the chordae tendon departing from the papillary muscles,front and rear septum tendon chordae presentation describing them septal papillary muscles. Most commonly,straiht papillary muscle chordae, front and rear, detach from their peak or immediately near it. Regardless of the detachment of the chordae, specific form that is most commonly beam valve chordae and chordae tendon rarely simple, unique.

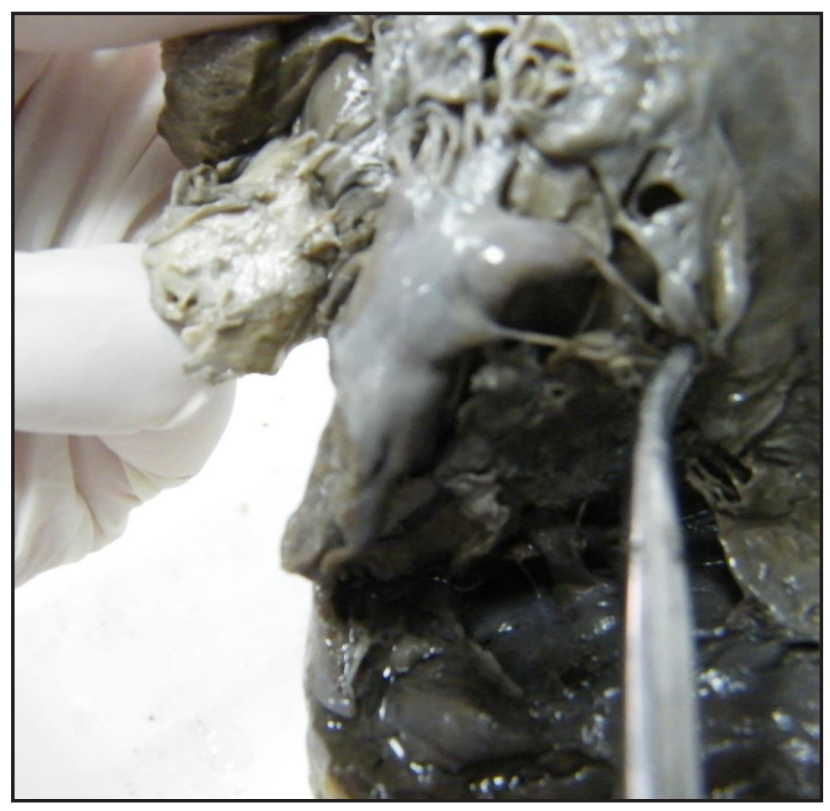

Figure 2. posterior papillary muscle as cylindrical, which presents four cones, and its upper extremity muscle detached from the valve chordae. From the middle of the face medial muscle emerges a cone and gives a closer stringing valvular branched to the septal valve.

Chordae tendon bundles can sometimes be joined at their base, giving rise to 106 unterior 
bunches of valvular chordae and will branch out into different levels: close tothe origin, halfway between the papillary muscle and valve, or closer to the valve. Simple valve chordae at its origin, can remain such until their insertion valve or valve chordae can branch out 2-3.

There are rare cases where the valve chordae come off the upper third of the papillary muscle, above or at its waist level or even at the base of implantation, with or without the presence of a muscular cone. Chordae of beams, can detach linking the papillary muscle of the ventricular wall or chordae tendon that connects between the papillary muscles in the same group or different groups, in some cases going above neighboring papillary muscle. These we called chordae or papillary-parietal muscle or interpapillary chordae.

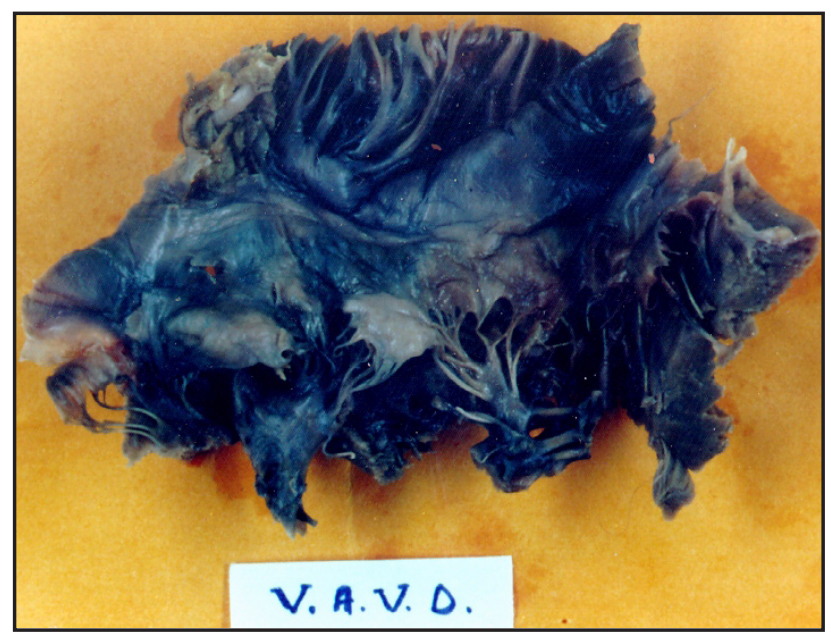

Fig. 3. The right posterior papillary muscles, irregular, unique, widened the basis of, the valve chordae emerging from the top to the middle of his face, lateral and medial.

There are situations in which the muscular bodies of a papillary muscle are joined by strips of muscle, that can give the appearance of a letter $(\mathrm{N}, \mathrm{Y}, \mathrm{H})$, or muscle decks bound to the papillary muscle of the ventricular wall, strengthening thus securing its base. Transverse or oblique muscle decks that are joining the two muscular bodies may have originated the valve chordae, or chordae may originate and the space between two cones of the upper end of the papillary muscle. I found the right ventricle tendon's chordae length between $5.5 \mathrm{~mm}-11.0 \mathrm{~mm}$, the longest being the septal which reached to $11.0 \mathrm{~mm}$, those of the posterior cusp ranged from 5.5 to $10.0 \mathrm{~mm}$, while those of the anterior leaflet were $8-9 \mathrm{~mm}$.

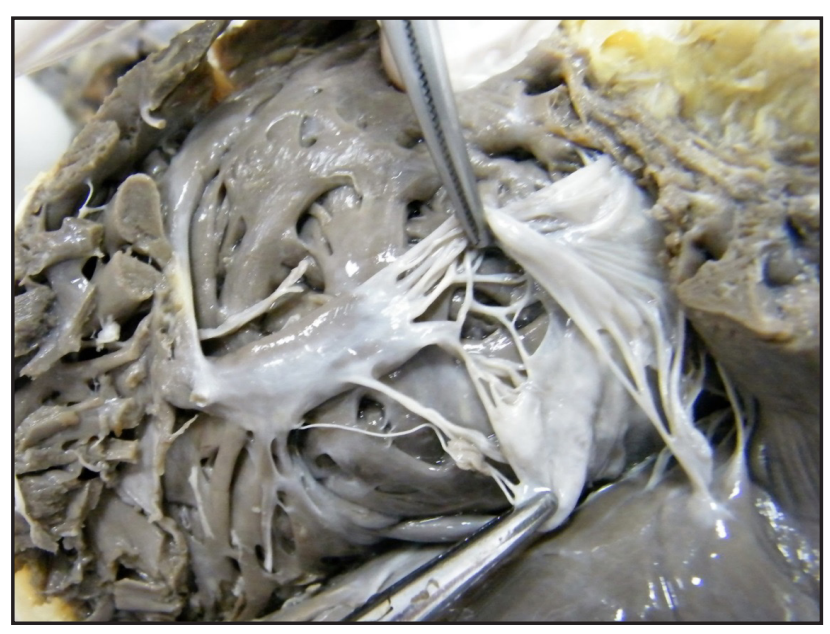

Fig. 4. Anterior papillary Muscle single, cylindrical medial base by inserting themselves with three fleshy trabeculae together with the ventricular wall. A valve chordae beam falls off the face of the anterior-medial face of papillary muscle and a tendon stringing valvular detach from the base of the medial papillary muscle.

\section{Eonclusions}

In the right ventricle, the papillary muscles exhibit great variability in the number, size, position and disposition of tendon cordae $(5,4,6)$. These aspects are important for the clinic, with papillary muscles playing an important role in the contraction of the right ventricle and in the closing of the tricuspid valve, preventing the ventricular blood from returning to the right atrium $(5,4,6)$. For the surgeon, they are important in repair procedures, papillary muscle dysfunction, replacement of the mitral valve (5).

It is noted that the large variability of the papillar muscles of the right ventricle in terms of the number, shape, tendon chordae that depart from their level, as well as the existence of the connections between the muscular bodies of the papillary muscles, between the two or three papillary muscles, as well as the bonds that exist between the papillary muscles and the corresponding ventricular wall. The importance of studying papillary muscles is particular for the morphologist, but especially for the practitioner, especially the cardiac surgeon. After (7), the papillary muscles begin to contract before to the ventricular contraction. They stretch the tendon chordae and draw the cusps. Their contractions 
last throughout the ventricular systole, thus preventing the blood to refill in the atrium.

\section{References}

1. Kavimani M., Johnson WMS, Jebakani C.F. (2011). Morphology of mitral papillary muscles -the bridges of vital link across the heart muscles. National J.Basic Med. Sciences (NJBMS), 2(1), 18-22.

2. Gunnal S.A., Wabale R.N., Farooqui M.S. (2013). Morphological variations of papillary muscles in the mitral valve complex in human cadaveric hearts.

3. Solomon V., Nayak M.V. (1995). Variations in the papillary muscles of the normal mitral valve and their surgical relevance. J.Card. Surg., 10(5), 597-607.
4. Xanthos Th., Dalivigkas I., Ekmektzoglou $\mathrm{K}$. Anatomical variations of the heart valves and papillary muscles of the right heart. Italian J. Anat.Embr. 2011, 116, 2: 111-126

5. Hosapatna M., D. A. Souza, A. Das, S. Padmashali, Ankolekar V. Souza A.D.S. Morphology of human papillary muscles in adults: a cadaveric study. J Heart Valve Dis 1995; 4 (suppl 2): 115-23

6. Gheorghitescu (Janca) Ruxandra, Toba M., Iliescu D.M., Bordei P. Morphological features of papillary muscles in the right ventricle . ARS Medica Tomitana - 2016; $3(22): 135-144$

7. K. Moore, Dalley A. Anatomy doctor. Aspects fondamentaux et Cliniques applications. Ed. De Boeck Université, Brussels, 2001, pp. 127-131.Sing.Med.J. 54(1), 44-48. 